\title{
Equoterapia: o cavalo como símbolo na construção de autoconhecimento
}

\section{Hippotherapy: the horse as symbol in the construction of self-knowledge}

\author{
LAÍSA ROSSATO'
}

Resumo: Este trabalho tem por objetivo investigar e compreender, na medida dos limites de um artigo, as possíveis semelhanças e divergências entre: a busca de autoconhecimento do homem e o simbolismo animal, especificamente ao simbolismo do cavalo. A busca do autoconhecimento é apresentada por Carl Gustav Jung (1875-1964), como a busca de simesmo, expressão da totalidade do ser, partindo de uma visão psicológica e espiritual, tendo como base a natureza animal, isto é, instintiva do homem. A simbologia animal, por sua vez, não se limita às aparências dos animais, quanto a sua fisiologia, mas à percepção da essência real íntima da natureza e do mundo, referindo-se não propriamente aos animais, mas à ideia que o homem tem deles e, talvez, a ideia que os homens têm de si próprios. Sabe-se que, na prática da Equoterapia, o cavalo opera como 'instrumento vivo' que proporciona bem-estar e melhoria na qualidade de vida dos praticantes; considerando-o como símbolo, é possível estabelecer um paralelo entre a busca de autoconhecimento e a prática da Equoterapia: o contato e a interação com o animal operam como forma de resgate e completude da totalidade do ser humano. Nossa proposta é, pois, uma leitura simbólica do cavalo e de sua relação imediata com o praticante.

Palavras-chave: Autoconhecimento. Simbolismo animal. Equoterapia. Jung.

Abstract: This work aims to investigate and understand, within the limits of an article, the possible similarities and divergences between: the search for self-knowledge of man and animal symbolism, specifically the symbolism of the horse. The search for self-knowledge is presented by Carl Gustav Jung (1875-1964), as the search for the self, an expression of the totality of being, starting from a psychological and spiritual view, based on the animal nature, that is, instinctive of the man. Animal symbology, in turn, is not limited to the appearance of animals, as far as their physiology is concerned, but to the perception of the real inner essence of nature and the world, referring not to animals, but to man's idea of them and, perhaps, the idea that men have of themselves. It is known that, in the practice of Riding Therapy, the horse operates as a 'living instrument' that provides well-being and improves the quality of life of practitioners; considering it as a symbol, it is possible to establish a parallel between the search for self-knowledge and the practice of hippotherapy: contact and interaction with the animal operate as a way of rescuing and completing the totality of the human being. Our proposal is, therefore, a symbolic reading of the horse and its immediate relationship with the practitioner.

Keywords: Self-knowledge; Animal symbolism; Hippotherapy; Jung.

\section{Introdução}

Eu tenho uma égua, que é indomável, que é brava, e medrosa, quando olho para ela, me sinto intrigada, e fico pensando: porque será que ela é assim? Quando eu olho para ela, tentando descobrir: o porquê ela se comporta dessa maneira, eu

\footnotetext{
${ }^{1}$ Unioeste - PR. E-mail: rossatolaisa@gmail.com
} 
começo a perceber, que tenho que olhar para alguns aspectos meus, e por vezes, me identificar com ela; posso pensar: o que será que ela passou para ser dessa forma? Eu começo a partir dela, ter que olhar para mim, começo então, a investigar, e penso: mas ela é assim por algum motivo. Pensando a partir de mim, com o aparato que eu tenho para desenvolver uma ideia sobre ela, pode ser que coisas que me venham em mente, nem estejam relacionadas a ela, mas que eu posso através de mim, estar olhando para ela, e nessa interação: entender ela e a mim mesma.

Isso é o símbolo, a égua se apresenta como: a parte visível das forças invisíveis do meu inconsciente; ele revela os segredos do inconsciente, conduzem às mais ocultas ação, abrem o espírito para o desconhecido e o infinito: dando forma aos desejos, incitam a empreendimentos, modelam o comportamento, provocam os êxitos ou derrotas; a interação com o símbolo pode ocorrer em uma interação com um objeto concreto, no momento em que ao olhar para o objeto, eu olho para mim, ao "falar" com o objeto, o objeto "fala" para mim. Isso ocorre pela transmissão de uma sensação, de um significado subjetivo, e vivo. Percebo, então, que: minha égua não gosta de pessoas, como se as pessoas provocassem medo nela, e me surpreendo, ao perceber que também tenho medo das pessoas. (Robert, 1986, p. 77)

A proposta desse artigo é contribuir para o enriquecimento da prática da Equoterapia, trazendo a está, a possibilidade de se estabelecer uma relação, entre, cavalo e praticante onde o cavalo, opere como um símbolo: associando-o a busca de autoconhecimento.

Apresentar-se-á neste artigo, uma reflexão, acerca da compreensão, e desenvolvimento do conceito de símbolo, enfatizando a sua distinção, ao conceito de signo; o cavalo enquanto símbolo; o corpo e o símbolo e; a Equoterapia e autoconhecimento.

Nesse encadeamento, ver-se-á relatos, e trechos do filme: The Horse Whisperer; como forma ilustrativa de como, a interação do praticante com o cavalo, operam como: forma de resgate a completude da totalidade do ser. Assim como: "os simbolistas não deixaram de estabelecer analogias entre animais e o ser humano [...]", na prática da Equoterapia, essa estratégia, pode ser adotada, buscando através da relação cavalo-praticante, o sentido de colaboração e de respeito, além, da busca do autoconhecimento. (RONECKER, 1997, p. 81)

Neste sentido, apontamos: uma nova proposta da Equoterapia, como aberta não só para pessoas com deficiências, mas, para praticantes em geral em busca de autoconhecimento.

\section{Símbolo e signo}

Para melhor compreensão e desenvolvimento do conceito de símbolo, faz-se necessário observar, sua relação com o uso da palavra: significado e o conceito de 
signo.

Em seu livro, Ego e Arquetipo, Edinger afirma que: "O símbolo está vinculado ao uso da palavra "significado" de modo particular" (p.182). A palavra significado é aplicada quando se faz necessário estabelecer uma relação de reconhecimento, de apreço, valor, importância, significação e significância. Em um sentido mais profundo, pode ser explanada de acordo com a questão existencial: "Qual o sentido $e$ significado da vida?” (1972)

Atualmente, a busca do significado da vida é projetada na objetividade: em coisas externas, como a vida de conforto material a aquisição de conhecimento, status, e relações sociais. Como afirma Edinger (1972), "procura-se o sentido humano onde ele não está: nas coisas externas, na objetividade” (p. 157)

O fato de não separarem as duas diferentes formas de se utilizar a expressão "significado", leva as pessoas a fazerem a pergunta sem resposta:

[...] “Qual o significado da vida?”. Essa pergunta não pode ser respondida dessa forma, pois confunde o significado objetivo e abstrato com o subjetivo e vivo. Se a refizermos de modo mais subjetivo, perguntando "Qual é o significado da minha vida?", ela passa a ter condições de ser respondida. (EDINGER, 1972, p. 156)

Neste sentido, precisamos distinguir as duas diferentes formas de uso dessa expressão: enquanto signo indica conhecimento abstrato e objetivo, um veículo de representação, se relacionando com significados abstratos e objetivos. Em outro momento, enquanto símbolo: refere-se a outro tipo de significado, "um significado vivo que não se relaciona ao conhecimento abstrato, mas sim um estado psicológico que pode iluminar a vida. (EDINGER, 1972, p.156)

A diferenciação, entre o objetivo e abstrato, veiculado por um signo; e o subjetivo e vivo, veiculado por um símbolo: vem de encontro com a necessidade urgente de descobrimos o mundo subjetivo interno da psique, suplantando a psicologia coletivista, genérica e de massas que procura o sentido humano, onde ele não está: nas coisas externas, na objetividade, que se posiciona desacreditando da ideia de uma personalidade ímpar e individual. (EDINGER, 1972)

Em busca do sentido de sua vida, indo de encontro consigo mesmo, vivendo em um mundo onde necessita se comunicar e desenvolver uma linguagem, com função de se relacionar com outrem: "O homem necessita de um mundo de símbolos, assim como de um mundo de signos”. (ENDINGER, 1972, p .158).

Parafraseando Edinger, tanto o signo quanto o símbolo são necessários, mas não devem ser confundidos entre si. O signo é morto, e o símbolo é vivo, pois diferente do símbolo, o signo é uma unidade de significado que representa uma entidade conhecida, o que nomeamos e atribuímos valor como as palavras e a forma de comunicação: como a língua. O símbolo, por outro lado, representa uma 
entidade viva e orgânica, que age como um mecanismo de liberação e de transformação de energia psíquica, sendo uma imagem ou representação de algo essencialmente desconhecido: um mistério. "O símbolo é dotado de um dinamismo subjetivo que exerce sobre o indivíduo uma poderosa atração e um poderoso fascínio". (EDINGER, 1972, p. 158)

Segundo Edinger, fazemos referência ao símbolo quando descrevo uma experiência significativa:

\begin{abstract}
Uma experiência desse tipo não veicula significado abstrato, ao menos basicamente; ela traz consigo, na realidade, um significado vivo que, carregado de afeto, nos põe em relação orgânica com a vida como um todo. Os sonhos, os mitos e as manifestações artísticas transmitem essa sensação de significado subjetivo e vivo, bem diferente do objetivo e abstrato. (EDINGER, 1972, p.156)
\end{abstract}

Para melhor compreendemos a transmissão de um significado subjetivo e vivo, que acontece quando estamos diante de um símbolo, podemos fazer uma simples distinção entre dois tipos de observação relacionados ao animal: “cavalo”. Enquanto signo, "cavalo" significa uma espécie particular de animal quadrúpede, porém diante da experiência vivenciada e relatada por mim opera como símbolo. (EDINGER, 1972)

Relato da experiência: "Hoje estava desanimada com um monte de coisas para fazer e cansada, quando chego na hípica e vejo o domador montado em minha égua manca que quase morreu, a qual um dia me disseram que nunca poderia ser montada, algo dentro de mim se desperta, ganha ânimo".

Essa experiência opera transformando a energia psíquica, pois ao mesmo tempo em que eu interagia com esse fenômeno externo, algo se transformava dentro de mim, como se me dissesse: "você também é capaz"; transmitindo assim, uma sensação de um significado subjetivo e vivo, através da manifestação do símbolo como uma projeção. (EDINGER, 1972)

Conforme a experiência acima relatada, o fato de algo ter sido transformado dentro de mim no momento em que olhei minha potra, sem que ao menos eu esperasse que isso ocorresse, modificando minha postura diante da realidade em que me encontrava, pode ser associado ao que Edinger (1972) e Robert (1986) dizem sobre a interação com um símbolo: que pode acontecer de forma espontânea e inconsciente, transmitindo ao indivíduo uma energia vital. De acordo com Edinger: "Não é possível fabricar um símbolo; só é possível descobri-lo" (1972, p. 158), eles são um produto espontâneo da psique arquetípica, sendo portadores de energia psíquica. Parafraseando Robert (1986), eles revelam os segredos do inconsciente, conduzem às mais ocultas ação, abrem o espírito para o desconhecido e o infinito, dando forma aos desejos, incitam a empreendimentos, modelam o comportamento, provocam os êxitos ou derrotas; transmitindo ao indivíduo, de forma consciente ou inconsciente energia vital que o apoia, orienta e o motiva. (p. 77) 
Os símbolos são gerados pelo inconsciente, podemos aprender a perceber esses símbolos, e a se relacionar com eles de forma consciente: podendo assim perceber a ação do inconsciente dentro de nós. (Robert, 1986, p. 29). Isso ocorre pois de acordo com Edinger: "A psique arquetípica mantém uma incessante atividade de criação de uma corrente estável”; despertos ou não essa corrente de símbolos, carregada de energia afetiva, continua e fluir sem que o ego se aperceba.

Os símbolos penetram no ego, levando-o a identificar-se com eles e a trabalhar com eles inconscientemente; ou passam para o ambiente externo, através das projeções, levando o indivíduo a ficar fascinado e envolvido com objetos e atividades externos (Edinger, 1972, p. 158)

De acordo com Edinger, é importante compreendermos que a psique e a subjetividade de um indivíduo, não possuem somente influências de reflexos do ambiente, das pessoas ou das relações de desejo. (1972, p.157). A importância de olhar para vida simbólica, e entender o efeito e dinâmica do indivíduo em relação com o símbolo, vem de encontro como a necessidade de busca de sentido, um sentido que se relacionada de forma subjetiva, e única a cada indivíduo; pois conforme Chegalier, Gheerbrant, descrevem em sua obra, Dicionário de símbolos (1982),: “[...] a percepção do símbolo é eminentemente pessoal, não apenas no sentido em que varia de acordo com cada indivíduo, mas também no sentido de que procede da pessoa como um todo" (p. XVI). Embora cada indivíduo participe de uma herança biofisiopsicológica, sendo influenciado pela cultura, ele também possui uma experiência única.

Considerando a importância da busca de sentido e significado eminentemente pessoal, subjetiva e única, que pode ocorrer a partir de um relacionamento do indivíduo com o símbolo, apontaremos três possíveis padrões de relação entre o ego e o símbolo, pois como afirma Edinger: "A relação entre o ego e o símbolo constitui um fator extremamente importante” (1972, p. 159).

Citando Endinger (1972), o primeiro padrão possível de relacionamento entre o ego e o símbolo, “[...] o ego pode identificar-se com o símbolo. Nesse caso, a imagem simbólica será vivida concretamente. O ego e a psique arquetípica serão uma só entidade" (p.159). Em geral: "[...] o indivíduo é incapaz de distinguir entre os símbolos da psique arquetípica e a realidade concreta, exterior. As imagens simbólicas são experimentadas como fatos reais, exteriores”. (1972, p. 159)

Exemplos desse tipo de relação são as alucinações dos psicóticos e as superstições de todo tipo. As misturas confusas das realidades psíquicas e físicas, tais como a prática da alquimia e da astrologia, e os cultos atuais para a obtenção de cura encontram-se nesta categoria. Sempre que se é tentado aplicar uma imagem simbólica a fatos físicos externos, com o propósito de manipular esses fatos em proveito próprio, coremos o risco de sucumbir. 
Os símbolos só existem efeitos válidos e legítimos quando servem para modificar o nosso estado psíquico ou nossa atitude consciente. Seus efeitos serão ilegítimos e perigosos quando aplicados, de forma mágica, à realidade física. (EDINGER, 1972, p. 159)

Na seguinte citação veremos como Edinger, aborda e discute a segunda e possível relação que pode ser estabelecida entre o ego o símbolo.

Na segunda possibilidade comete-se o erro oposto, o ego pode estar alienado do símbolo. Neste caso, a significação do símbolo se perde por ser tomada apenas como signo de algum conteúdo conhecido; embora a vida simbólica não possa ser destruída, nesse caso ela funcionará de forma degradada, fora da consciência. O símbolo será reduzido a signo. As necessidades misteriosas e urgentes do símbolo só serão compreendidas em termos de fatores elementares e abstratos. (EDINGER, 1972)

Essa relação tem como base, a atitude racionalista que supõe poder ver além dos símbolos, descobrindo seu significado "real". No entanto esta abordagem reduz todas as imagens simbólicas a fatores elementares, conhecidos. Operando com de forma redutivista, defendendo a ideia de que: “[...] não existe verdadeiro mistério, nenhum elemento essencial desconhecido que transcenda a capacidade de compreensão do ego" (p.16o). Desta forma, "nos termos dessa concepção, não pode haver símbolos verdadeiro; há apenas signos”. (EDINGER, 1972, p. 16o)

Edinger (1972) salienta que esses dois padrões de relação entre o ego e o símbolo podem ser considerados como dois estágios sucessivos do desenvolvimento da personalidade. Onde o primeiro estado, ocorre uma identificação entre o ego e os símbolos inconscientes se caracterizando como: o estágio inicial do desenvolvimento do ego, presente, por exemplo, no primitivo e na criança. No estágio posterior, tem como base um estado de alienação entre o ego e o simbolismo do inconsciente; como um estágio posterior do desenvolvimento, “[...] talvez uma reação necessária contra o estágio antecedente de identificação entre o ego e o inconsciente". (p.162). Essa "[...] dissociação entre o ego e o inconsciente que, mais cedo ou mais tarde, deverá, se quiser alcançar a totalidade ser superada”. (EDINGER, 1972, p.162)

O ego identificado com a imagem simbólica como relatado na primeira possibilidade de relação entre o ego e o símbolo, torna-se vítima dessa imagem, condenado a viver concretamente e de forma inconsciente o significado desse símbolo, em vez de entendê-lo conscientemente. "Quando o ego é identificado com a psique arquetípica, o dinamismo do símbolo só será visto e experimentado como um impulso para a luxúria ou para o poder". (EDINGER, 1972, p.163)

Neste momento vamos nos atentar a terceira e desejável possibilidade. O ego é receptivo aos efeitos das imagens simbólicas. As imagens simbólicas que se 
manifestam na psique consciente e podem ser apreendidos pelo ego. Parafraseando Johnson (1989), é por meio desta interação que essas duas realidades, consciente e inconsciente, podem dialogar e estabelecer uma ligação. Ou seja, é por meio dos símbolos que a consciência é capaz de apreender a dimensão inconsciente da psique, na qual estão contidos os arquétipos. Sendo os sonhos e a imaginação, caminhos naturais desenvolvidos pela psique para expressão desses símbolos.

Torna-se possível uma espécie de diálogo consciente entre o ego e os símbolos que emerge. Assim, o símbolo é capaz de realizar sua função própria de liberador e transformador de energia psíquica com plena participação do entendimento consciente. (EDINGER, 1972, p.159)

Essa atitude consciente, que ocorre com a participação do entendimento consciente em interação com o símbolo, traz ao indivíduo uma série de encontros numinosos entre o ego e a psique transpessoal, isso é opera produzindo um efeito despertador e transformador sobre a personalidade. "Descobre uma nova dimensão de significado que atribui um valor à subjetividade" (EDINGER, 1972, p. 172).

Robert ressalta que quando vivenciamos as imagens simbólicas é como se vivenciássemos "[...] partes interiores de nós mesmos que estão sob a roupagem das imagens". (1986, p. 34). O autor complementa afirmando:

Este é o poder da experiência simbólica da psique humana quando empreendida conscientemente: sua intensidade e seu efeito sobre nós são geralmente tão concretos como uma experiência física, seu poder de redirecionar nossas atitudes, de nos ensinar e nos fazer mudar em níveis profundos é muito maior que o dos acontecimentos externos pelos quais podemos passar sem nos aperceber. (Robert, 1986, p. 35)

Podemos vivenciar um símbolo e descobrir sua forma oculta por um processo de analogia. A Analogia neste contexto opera como ponto de referência, entre coisas diferentes: opera como um encontro entre a consciência e o inconsciente. Pois quando vivenciamos um símbolo, "[...] vivenciamos a entidade psíquica interior que é representada por esse símbolo". Na interação entre o ego e o símbolo, a imagem simbólica se coloca diante de nós, e diz algo. (Robert, 1986, p. 35). Quando me coloco diante de minha égua, (como no relato anteriormente citado) e sinto algo, pode ser um incômodo, fascínio, carinho, amor, uma emoção, em fim, ela não me diz nada concretamente, cavalos não "falam", mas, é como se me dissesse algo que por muitas vezes não diz respeito a ela, mas a mim mesma. Ela não me diz nada concretamente, mas é como se me dissesse: "Você também é capaz". É como se os conteúdos inconscientes de revestissem de uma roupagem para comunicar algo a psique consciente. Essa interação acontece em forma de analogia, como metáforas, para nos transmitir um sentido de uma realidade interior, única e intima de cada ser 
muito maior que os acontecimentos externos. (Robert, 1986)

\section{O cavalo como símbolo}

Edinger em sua obra, Ego e arquétipo (1972) afirma que: “o conceito de físico não é o único critério de verdade: há também realidades psíquicas que não podem ser explicadas, demonstradas ou contestadas sob nenhum ponto de vista físico". Uma experiência seja ela exterior ou interior: um sentimento ou uma sensação, por exemplo, representam uma realidade psíquica que não pode ser constatada, e que também dispensam demonstrações. (p. 162).

Nas palavras de Ronecker: "Dissecar um animal não ensina nada sobre sua natureza real. Para isto, é necessário compreender e amá-lo e identificar-se com ele”. (1994, p.11)

Parafraseando Edinger, todos enunciados simbólicos se referem a objetos que é impossível constatar do ponto de vista físico, plano no qual não tem nenhum sentido. Isso ocorre, pois, a psique é um fator autônomo, e o simbólico é confissão psíquica que têm por base, em última análise, processos inconscientes. "Esses processos são inacessíveis à percepção física, mas demonstram sua existência através das confissões da psique [...]”. (1972, p. 162)

O simbolismo animal não se refere aos animais propriamente ditos, mas a ideia que o homem tem deles e talvez se si próprio. Para que seja possível entender os animais como símbolos, Ronecker (1961) orienta: "Ouve o que diz o seu coração e compreendei o animal; é necessário amá-lo e, portanto, respeitá-lo”. (RONECKER, 1961, p.11)

De acordo com o autor supracitado, o ser humano possui uma natureza animal. Assim como o animal o homem também age por instinto: "o que o instinto se não inteligência natural e inata que o homem também deve ter possuído em idades remotas? (p. 14)

A tarefa aqui desempenhada de abarcar os aspectos simbólicos do cavalo é delicada, pois os símbolos possuem uma natureza desconhecida, difícil de reconhecer, em última análise impossível de definir. Em sua natureza inconsciente, deve ser considerado em seu significado em relação com a situação consciente, e em sua relação cotidiana do empírico. (JUNG, 2012, p. 44)

Nos atentaremos então, a aspectos gerais do simbolismo do cavalo enquanto arquétipo.

Parafraseando Hopche (2012), entende-se por arquétipos, padrões de percepção e compreensão psíquicas comuns a todos os seres humanos, contidos na camada mais profunda do inconsciente: no inconsciente coletivo, fonte psíquica de poder, totalidade e transformação interior. 
Os arquétipos estão muito próximos dos instintos como forma típica de proceder e forma repetitiva de reagir. Os instintos constituem as formas básicas de comportamento. Os arquétipos, por outro lado podem ser descritos como as formas básicas de visualização dos instintos. Jung refere-se a esse tema, dizendo, literalmente, que as figuras arquetípicas primitivas podem ser entendidas "como visualização do próprio instinto ou como autoretrato do instinto" (HARK, 1988, p. 21)

Olhando para a relação dos diversos mitos, parece que o cavalo é um dos "arquétipos fundamentais inscritos na memória humana”. Ele sem dúvida, o “[...] animal sacralizado por excelência, onde o cavalo vive, o homem quase o divinizou". (RONECKER, 1997, p. 300)

De acordo com Jung (2012), o cavalo enquanto animal representa a psique não humana, o infra-humano, a parte animal e, por conseguinte, a parte psíquica inconsciente; por este motivo encontramos no folclore os cavalos clarividentes e "clariaudientes", que às vezes até falam. Enquanto animais de carga, a sua relação com o arquétipo da mãe e das mais próximas (as valquírias que carregam o herói morto até Walhalla, o cavalo de Tróia, etc.) quando se apresentam como inferiores ao homem, representam o ventre e o mundo instintivo que dele ascende; o cavalo é "dynamis" e veículo, somos por ele levados como por um impulso, mas como os impulsos, está sujeito ao pânico, por lhe faltarem as qualidades superiores da consciência. (p.43)

Clarividente e familiar as trevas, com a esfera irracional, anunciam a morte, sendo portador tanto da vida quanto da morte, da água e do fogo. Exerce a função de guia para o além possuindo qualidade de psicopompo. (RONECKER, 1997, p. 301)

De acordo com o autor supracitado o cavalo é símbolo de riqueza, de sucesso e de dinamismo. Ele é a montaria do grande guerreiro e dos exércitos celestes, atravessa os mundos e transporta as almas. O cavalo urânico e solar se presta, pois, perfeitamente para ser a montaria dos heróis, dos Deuses, dos santos e dos conquistadores espirituais.

Jung complementa dizendo que quando em sonho ou trabalhos com a imaginação os cavalos não carregam cavaleiros mostra que os impulsos instintivos podem escapar do nosso controle consciente. "Nos cavalos reaparecem todas as forças positivas que lhe faltavam antes e que lhe eram tão necessárias". (2008, p. 226)

"Por sua suscetibilidade ao medo, ao pânico e aos encantamentos, o cavalo é frequentemente um símbolo da instintividade. No plano da psique individual, a imagem do cavalo desenfreado aponta para a dificuldade de domínio do eu diante da invasão de impulsos inconscientes". (RAMOS, BIESE, BALTHAZAR, 1999, p. 89) 


\section{O corpo e o símbolo}

A psique e o corpo são uma unidade indissolúvel, por uma limitação da compreensão da mente consciente ocorre que por inúmeras vezes essas duas instâncias são abordadas como duas partes distintas. Se assim se faz necessário abordá-las para uma melhor compreensão de como interagimos biológico e psiquicamente, devemos ter em mente que quando estamos falando de um corpo, estamos falando de um corpo ao qual possui um equilíbrio energético, que não depende apenas da ingestão de calorias e do gasto energético, mas de um corpo que se relaciona intimamente com questões psíquicas e somáticas. Quando abordamos fenômenos relacionados a psique, como o símbolo, esses fenômenos e interações ocorrem no corpo. Ora, onde sinto uma emoção, quando: penso, sinto, percebo, tenho um sentimento, uma impressão ou intuição; onde isso ocorre se não no corpo. Onde sinto o calor de uma emoção? No corpo. (WOODMAN, 1980)

Um dos aspectos desenvolvidos na interação entre o cavalo e o praticante, na prática da Equoterapia e a percepção corporal, pois, em relação com um corpo distinto: o corpo do cavalo, o praticante pode perceber seu próprio corpo, perceber os movimentos, a interação e os limites de seu próprio corpo. Uma pessoa com paralisia, por exemplo, estática em uma cadeira de rodas com seu corpo inerte possui uma percepção limitada de seu próprio corpo, porém em interação com o cavalo passa a receber estímulos sensoriais e motores, podendo assim dentro de suas limitações se perceber.

Na qualidade de psicóloga não estou qualificada para discutir os percursos bioquímicos e motores do corpo, meu interesse é pela totalidade dessas experiências. (WOODMAN,1980)

Segundo Mindell (1989), o corpo através das imagens simbólicas, liga-se a dimensão inconsciente da psique. Tomar consciência do corpo e de suas operações equivaleria a tornar-se consciente dos seus conteúdos inconscientes. Portanto o processo de auto-conhecimento, decorrente da conscientização de conteúdos inconscientes, também poderia ser observado no corpo. Tendo isso em mente devese compreender: a relação, a dinâmica, e interação de cada patologia, e sintomas presentes nos praticantes da Equoterapia em termos do símbolo. Nessa compreensão reside no tratamento a possibilidade de cura.

Modificações fisiológicas corporais aparecem em sonhos, e alterações de comportamento e atitude afetam a experiência corporal. (MINDELL, 1989, p. 42)

De acordo com Byington, citado em Ramos (2016) "[...] o corpo participa da psique através de símbolos estruturantes que expressam suas particularidades”(p. 50).

Existem várias expressões para se referir a essa interação entre o corpo e a psique, são elas: corpo sutil, corpo pneumático, inconsciente somático, corpo 
onírico, corpo subjetivo e corpo simbólico; todos esses conceitos se referem a qualidade simbólica da interação mente-corpo. (RAMOS, 2006)

Arnold Mindell em sua obra, O Corpo Onírico (1989) utiliza a expressão corpo onírico, que de acordo com o autor possui várias modalidades de expressão, podendo se expressar através de sintomas e doenças. Para ele a causa de uma doença pode estar ligada tanto a experiência corporal individual como vinculada a um material onírico e simbólico. Pode ocorrer que a doença traga conteúdos simbólicos transmitidos por sonhos e experiências corporais que indicam que o corpo onírico está operando. (p.42)

Mindell referencia uma distinção entre corpo real e corpo onírico, para nossa melhor compreensão dos aspectos fisiológicos e psíquicos presentes na manifestação do que ele chamou de corpo onírico. (1989)

O conceito de corpo real é de origem grega clássica. Ao corpo real é atribuído medidas filosóficas objetivas, sendo resultado de conceitos culturais. Ele é composto de órgãos, RNA, bactérias, células, doenças. Pode ser definido através de seu peso, tamanho, idade, formato, temperatura. (MINDELL, 1989)

Já o corpo onírico não possui uma estrutura mensurável, podendo ser apenas percebido, pois possui uma natureza rítmica, gasosa e fluida. "O corpo onírico pode ser percebido, mas não entendido em termos de corpo real" (MINDELL, 1989, p.32). Sendo assim para estudarmos o corpo onírico temos que deixar que ele se manifeste. O corpo onírico é sempre uma essência que permeia o corpo real e se estende para além deste. (MINDELL, 1989).

Ambos, corpo real e corpo sutil se relacionam, pois assim como as sensações do corpo são causadas pelo corpo real, o corpo real também sobre influências do corpo onírico.

"A compreensão empírica do relacionamento entre corpo real e corpo sutil é simplesmente que ambos são aspectos de uma coisa: o corpo onírico". (MINDELL, 1989, p. 42).

De acordo com o mesmo autor, Tendo em mente a compreensão empírica do relacionamento entre corpo real e corpo onírico, quando manifestada uma doença aparentemente apenas biológica ou fisiológica é necessária uma abordagem mais ampla em seu tratamento. O trabalho deve ser abordado o âmbito da significação do que está ocorrendo na vida da pessoa.

Considerando que o corpo onírico se relaciona com a experiência corporal e simbólica, aspectos do corpo tais como: gestos, comunicação, doenças e sintomas podem ser expressos de forma simbólica, assim como símbolos podem ser refletidos no corpo como sintoma. Os símbolos e sintomas devem ser trabalhados interpretados e vivenciados. Neste contexto "O corpo onírico não é encontrado 
como uma entidade em si, com características próprias, mas como um sintoma a ser superado" (MINDELL, 1990, p. 20).

Mindell (1985), citado em Ramos (2006), reconhece: "O trabalho psicoterapêutico leva a uma confluência entre corpo real e corpo onírico, pois este se aproxima cada vez mais do corpo real, emergindo ambos na criação da personalidade" (p. 66). A manifestação do corpo onírico como sintoma é considerado como o melhor meio para o desenvolvimento da personalidade, pois existem casos típicos de sintomas que "estão tentando motivar a pessoa efetuar uma mudança completa de personalidade” (MINDELL, 1990, p. 26).

Diante de uma doença ou sintoma o indivíduo se questiona e busca soluções para sanar a dor e o incomodo decorrentes dos sintomas, nas palavras de Mindell a partir da dor o indivíduo é obrigado a constatar a consciência, pois "sua alma lhe envia mensagens importantes através da doença" (1990, p. 20).

A conscientização pode ocorrer através da dor e não da luta contra essa dor. "As doenças podem ser auto curativas, o corpo onírico é a sua própria solução" (MINDELL, 1990, P. 21).

Esse trabalho de conscientização pode ocorrer através da interação do símbolo com o corpo. Podemos ter duas situações de manifestação do corpo simbólico, que pode ser vivido passiva ou ativamente.

Quando é constelado passivamente, temos, por exemplo a formação de sintomas e o surgimento de fantasias; quando é vivido ativamente, temos o estabelecimento de uma relação com o símbolo emergente, integrando- o na consciência. (RAMOS, 2006, p. 50)

Na tentativa de explicar reações psicossomáticas Marty, Muzam e David afirmam que pacientes psicossomáticos tem pobreza de mundo simbólico, pois possuem pensamento do tipo operatório, aprisionado no concreto, não possuem capacidade de simbolizar, reagindo somaticamente e provocando a formação de sintoma. Neste movimento o paciente tem pouca ligação com o inconsciente, possibilitando que o processo de somatização ocorra, pois, a doença orgânica é a falha de sentido e significação simbólica. (MARTY; MUZAM; DAVID, 1963 apud RAMOS, 2006).

Porém, Ramos (2006) aponta a existência de pacientes com somatizações que não possuem um pensar operatório. A autora apresenta uma perspectiva que defende a ideia de que o paciente, ao somatizar, vai além da circunstância de ele simbolizar ou não, mas que está simbolização ocorre no corpo, ou seja, no plano somático.

É possível que o problema esteja na interação da vida conscienteinconsciente. $\mathrm{O}$ paciente que se expressa somaticamente perdeu a conexão de seu corpo com seu inconsciente somático, de modo que 
a vida fantasiosa, eidética, encontra-se desconectada da vida orgânica. Isto é, esses pacientes têm uma vida simbólica, porém restrita e compulsiva. (RAMOS, 2006, p. 58).

A função simbólica, pode ficar fixada no corpo devido a não adequação a mediação psique-corpo, que pode acontecer na infância na relação parental primária, portanto, o sintoma tem um significado e um sentido, além de ser considerado um símbolo. (RAMOS, 2006).

O sintoma como símbolo, espelha uma estrutura psíquica, assim como, uma estrutura psíquica espelha um sintoma. Quando ocorre a emergência do símbolo na polaridade corpórea, é como se essa somatização fosse um convite ao paciente voltar-se, e se confrontar com seus complexos, e a corrigir seu desenvolvimento através da integração com o inconsciente. (RAMOS, 2006).

Os sintomas se originam nos complexos, entendido como: "[...] um grupo de representações psíquicas e o sentimento característico ligado a esse grupo de representações". (HOPCKE, 2011, p. 28). Os complexos possuem carga emocional, podem ser inconscientes, reprimidos ou inacessíveis, possuindo elementos relacionados ao insciente pessoal como também com o inconsciente coletivo. (HOPCKE, 2011)

Para Jung (1973 apud Ramos, 2006) o complexo enquanto sintoma não é reconhecido a nível abstrato, nem expressado na fantasia, imaginação ou sonho, por isso pode ter uma expressão orgânica, podendo conter mensagens psíquicas. "Assim, o sintoma orgânico contém mensagens psíquicas que não tem uma representação abstrata acessível à consciência” (Ramos, 2006, p. 6o).

[...] sintomas orgânicos correspondem a uma cisão na representação de um complexo, de maneira que a parte psíquica, abstrata, havia sido reprimida. O sintoma (símbolo) havia se desenvolvido de maneira automática e descontrolada, o que revelava seu caráter complexo, inconsciente. (RAMOS, 2006, p. 194).

A informação recalcada fica aprisionada no complexo produzindo sintomas repetitivos que reproduzem o erro, a cisão, devido à ausência de coerência entre múltiplos aspectos. (RAMOS, 2006).

De acordo com a autora supracitada, quando este fenômeno ocorre a consciência, está configurada, com uma postura unilateral, neste contexto o sintoma é uma manifestação inconsciente, com função compensatória, tendo a finalidade de religar: o ego com o Self através da integração do conteúdo reprimido.

A manifestação de uma doença, enquanto sintoma, pode estar além de seu significado, pois, nem sempre é possível atribuir um sentido ao adoecer, já que o sintoma não precisa estar necessariamente associado a um complexo infantil, podendo indicar o aparecimento de um novo símbolo. Podendo então ser a 
expressão de um aspecto desintegrado que precisa ser compreendido pela integração na consciência; sendo o símbolo expressões de estruturas psíquicas manifestadas no corpo, torna-se possível a percepção e o trabalho de conscientização que pode ocorrer de forma ativa, decorrente do estabelecimento de uma relação com o símbolo emergente, integrando- o na consciência. A integração do símbolo a consciência ocorre, pois um complexo tem sempre uma expressão simbólica corpórea, através da qual podemos ter a chave para a compreensão da doença. (RAMOS, 2006).

Segunda a mesma autora, o símbolo aponta para a disfunção, um desvio que precisa ser corrigido. A compreensão da doença, neste sentido, considera a doença como expressão da totalidade do ser, portanto, curar seria: “[...] interpretar corretamente o que essa totalidade está tentando expressar através dos sintomas e ensinar-lhe um modo menos doloroso de auto-expressão". (2006, p. 68)

Jung descreve vários métodos denominados amplificações, onde conteúdos inconscientes podem ser integrados a consciência, como: imaginação ativa, uso de pintura, e argila. Considerando a totalidade, e subjetividade dos praticantes da Equoterapia, seus sintomas e expressões corporais, juntamente com o conteúdo apresentados neste artigo, será a Equoterapia uma prática que gozará a possibilidade, de um dia se tornar mais um método de amplificação, assim como a imaginação ativa, e outras técnicas expressivas se tornaram?

\section{Equoterapia e autoconhecimento}

Segundo Traumutt (2003 apud Ferrari, 2009) os animais são utilizados como uma ferramenta terapêutica nos mais diversos ambientes como: escolas, hospitais, centro de tratamento, entre outros.

Machado e Rocha, (2008) abordam a terapia assistida por animais como uma prática onde o animal é a parte principal do tratamento, que tem como objetivo, promover a melhora social, emocional, física ou cognitiva de pacientes humanos. Ela parte do princípio de que o amor e a amizade que podem surgir entre seres humanos e animais geram inúmeros benefícios.

No âmbito da psicologia e da reabilitação, na relação pessoa-animal, sempre se percebe troca que gera ganhos psíquicos e físicos e, nesse caso, a maior beneficiada é a pessoa que pratica equitação, sendo esta então, considerada mais do que um simples esporte ou lazer, pois vai além. (FREIRE, 1999 apud ADÁRIO, 2005, p. 50)

Segundo Jung (2008), nossa psique está de certo modo, conectada ao mundo inteiro, tanto interior como exteriormente. Todas as manifestações da vida estão, de certa maneira, sintonizadas com o contínuo espaço-tempo. Observando o comportamento dos animais é possível perceber que seus esquemas instintivos se 
encontram perfeitamente ajustados e adaptados, os levando a se comportarem de acordo com uma configuração instintiva universal. "Foi com essas considerações em mente que um zoólogo famoso logo declarou que o "interior" de cada animal se estende amplamente sobre o mundo à sua volta, "psiquificando" tempo e espaço". (JUNG, 2008, p. 275)

Ademais:

De modo que foge totalmente a nossa compreensão, o nosso inconsciente também está sintonizado com o nosso ambiente nosso grupo, a sociedade em geral e, além de tudo, com o contínuo espaço-tempo e a natureza no seu todo. (JUNG, 2008, p. 276)

Para Jung (1978), as pessoas se relacionam com o mundo por meio de símbolos.

Cada animal, enquanto representação simbólica, é uma referência de nosso labirinto interior, cujo percurso, muitas vezes difícil e doloroso, é o caminho iniciático de nosso desabrochar enquanto indivíduos nos ciclos cósmicos da evolução espiritual. (RONECKER, 1997, p. 79)

Considerando o animal como representação simbólica, e a amplitude da psique que se estende em conexão e interação com o ambiente no espaço-tempo. $\mathrm{O}$ homem em sua interação com o ambiente, ou com o cavalo encontra-se ligado ao animal em união mítica para o bem ou para o mal. $\mathrm{O}$ homem não pode se privar de pensar, representar e simbolizar o animal, pois isso está em sua natureza. (RONECKER, 1997, p. 18)

Citaremos o filme The Horse Whisperer (1998), para melhor compreensão da proposta aqui apresentada, onde a prática Equoterapia e a interação com o cavalo operam como uma forma de resgate e completude da totalidade do ser humano, através do autoconheciemento.

O filme conta a história de Grace, e sua família. Grace sofre um acidente enquanto cavalgava com sua amiga Judith: enquanto Grace tentava socorrer sua amiga que cairá de seu cavalo, um caminhão as atinge, Pilgrim seu cavalo se joga contra o caminhão como se tentasse protegê-las, ele fica gravemente ferido, Judith morre e Grace sobrevive, porém, uma de suas pernas fora amputada, pela gravidade dos ferimentos. Ambos Pilgrim e Grace ficam enfermos e doentes após escaparem da morte.

A partir desse pequeno relato inicial do filme, podemos perceber uma profunda ligação e identificação do homem com o cavalo. Em sua obra, Os animais e a psique: do simbolismo a consciência, as autoras relatam que: "O herói e seu cavalo muitas vezes têm o mesmo destino. Ao conduzir o herói através da neblina, do fogo e da água, ao permanecer ao seu lado nas situações difíceis, ele entrelaça sua vida à 
do dono e chega até a morrer com este”. (RAMOS, BIESE, BALTHAZAR, 1999, p. 87)

Nos identificamos parcialmente com os animais, eles são reflexos de nossa natureza complexa, operam como espelhos, espelhando nossos instintos domesticados ou selvagens. Muitas vezes o ser humano se serve do animal para denunciar, através do simbolismo, seus próprios defeitos ou para exaltar suas virtudes. (RONECKER, 1997, p. 79)

Pilgrim o cavalo do filme opera como espelho dos instintos, no momento em que Annie, a mãe de Grace, olha para Pilgrim, o cavalo, que se encontrava ferido externamente e interiormente, pois, o cavalo não era mais o mesmo: vivia assustado e ninguém podia chegar perto dele. No momento em que Annie o olha, percebe que o mesmo acontecia com Grace - a perna de Grace já estava cicatrizando, mas ela precisa curar o resto de si-mesma também.

Em um diálogo de Grace e Annie, Grace diz que Pilgrim, o cavalo, deveria ser abatido, pois não era justo fazê-lo sofrer, ela complementa dizendo: "Talvez eu também deva ser abatida, eu não sirvo para mais nada”. Diante dessas circunstâncias, Annie vai até Montana levando com ela Pilgrim e Grace, ela vai atrás de Tom Booker, o chamado encantador de cavalos.

Ao domesticar o cavalo, o homem fez dele uma extensão de seu corpo. Aprendeu com ele a ser forte e valente, e ampliou seu contato com o mundo quando lhe foi possível percorrer longas distancias em menos tempo. O cavalo também possibilita ao homem entrar em contato com seu lado instintivo, adquirindo maior domínio sobre si mesmo. A direção da relação entre cavalo e cavaleiro é determinante nesse processo. Uma vez que tal relação se estabeleça de modo positivo e o cavaleiro seja capaz de dirigir essa energia, os instintos passam a ser seus auxiliares nas situações difíceis [...] (RAMOS, BIESE, BALTHAZAR, 1999, p. 87)

Tom Booker, o encantador de cavalos, começa a realizar um processo de doma em Pilgrim, onde Grace também deverá participar do processo. Tom se relaciona com Pilgrim com muita dedicação paciência e respeito. Grace se sente rejeitada, incapaz, e com medo. Participando do processo de doma, junto com Pilgrim e Tom, a medida que Pilgrim vai mudando de atitude, Grace começa a se abrir, e descobrir que também é capaz de superar seus medos e emoções negativas, adquirindo assim maior domínio sobre si mesma e suas emoções.

Assim como “[...] os simbolistas não deixaram de estabelecer analogias entre animais e o ser humano [...]", na prática da Equoterapia esta estratégia pode ser adotada buscando através da relação cavalo-paciente o sentido de colaboração e de respeito, além da busca do autoconhecimento. (RONECKER, 1997, p. 81)

Carl Gustav Jung, psiquiatra e psicoterapeuta que fundou a psicologia analítica, em sua obra Presente e futuro (2011), aborda o autoconhecimento, como um 
processo que vai além das características da personalidade conhecidas pela consciência, através de sua interação social e de uma definição a partir de sua interação com as outras pessoas, podemos dizer: "eu sou calma, intelectual, esperta, introvertida, etc." Pode-se desta forma conhecer seus próprios conteúdos, porém de uma forma limitada.

Segundo Jung (2012)

$\mathrm{O}$ eu, no entanto, só conhece os seus próprios conteúdos, desconhecendo o inconsciente e seus respectivos conteúdos. $\mathrm{O}$ homem mede seu autoconhecimento através daquilo que o meio social sabe normalmente a seu respeito e não a partir do fato psíquico real que, na maior parte das vezes, é a ele desconhecido. (Jung, 2012. p.13)

Quem progredir no processo de autoconhecimento, segundo a perspectiva de Jung, trará inevitavelmente à consciência, conteúdos do inconsciente: ampliando a âmbito de sua personalidade. "Todo esse material acrescido à consciência determina uma considerável ampliação do horizonte, um aprofundamento do autoconhecimento e, principalmente, humaniza o indivíduo, tornando-o modesto”. (JUNG, 2011, P. 25)

Neste sentido, o autoconhecimento é abordado como a investigação da própria alma, pois, através desta "ampliação" da consciência, os conteúdos do inconsciente, passam a ser liberados e conscientizados através da análise. Abordando o inconsciente, pode-se deparar com conteúdos reprimidos: desejos, lembranças, tendências, planos etc.., como também, com instintos e seu mundo de imagens, que: "[...] pode constituir um passo no sentido de esclarecer as forças adormecidas de nossa psique que, embora presentes, passam quase desapercebidas [...]" pela consciência. (JUNG, 2012, p. 25)

"[...] O cavalo simboliza, na psique individual, a possibilidade do despertar da criatividade humana. Desse modo, pode ser visto como um elemento facilitador do acesso à energia renovadora do inconsciente”. (RAMOS, BIESE, BALTHAZAR, 1999, p. 91)

Para melhor compreensão do processo de autoconhecimento, proposto por Jung, é necessário tratarmos do que se entende por consciência e inconsciente, pois, o processo de autoconhecimento se dá pela conscientização de conteúdos inconscientes. (JUNG, 2012, p. 25)

Nas palavras de Helmut Hark (1988), em sua obra, Léxico dos Conceitos Junguianos Fundamentais a partir dos estudos de C. G. Jung, podemos declarar, um melhor entendimento acerca do conceito de consciência.

Se imaginarmos a psique sob a forma de uma esfera, em sua totalidade consciente-inconsciente, a consciência seria um pequeno 
retalho de toda a superfície, enquanto o ego seria o centro deste campo. Consciente é tudo aquilo que o ego percebe e sabe. A consciência é um órgão de percepção que registra e interpreta as múltiplas relações com o mundo e os símbolos do inconsciente, classificando-os como palavras e conceitos. (HARK, 1988, p. 39)

A consciência é um conceito necessário de oposição ao inconsciente, é um "órgão de orientação", através dela percebemos a realidade exterior e interior, interpretamos o que foi percebido podendo dizer do que se trata, podemos classificar as "informações" lhe atribuindo um valor. (HARK, 1988, p. 39)

Neste sentido, a consciência se mostra como uma função importante de estruturação e de atribuição de sentido. É extremamente importante para o domínio dos impulsos e instintos humanos. Essas funções poderiam ser comparadas a um cavaleiro que guia compenetradamente seu cavalo. (HARK, 1988, P. 39)

Segundo o mesmo autor, já o inconsciente contém todas as experiências e conteúdos psíquicos, que não se relacionam, de maneira perceptiva, nem com a consciência nem com o ego.

Para Johnson (1989), o inconsciente é como um campo de energias muito mais extenso que a mente consciente. Este campo de energia possui conteúdos que vão além dos conteúdos reprimidos, pois, o inconsciente possui outros aspectos além deste: como todo restante do material que está submetido ao limiar da consciência.

De acordo Jung (2012), o inconsciente possui conteúdos de caráter pessoal, impessoal e coletivo. $\mathrm{O}$ inconsciente pessoal contém aspectos das experiências pessoais, percepções, recordações esquecidas ou reprimidas, que são produzidas ao longo da vida do sujeito. Já o inconsciente coletivo, contém categorias herdadas, arquétipos e conteúdos relativamente ativos. "Esses estão além das aquisições e elementos pessoais". (p. 466)

De acordo com o autor supracitado, dificilmente abordaremos o conceito de consciência e autoconhecimento sem fazermos menção aos conteúdos inconscientes, isso ocorre pois “ '[...] O que é consciente é conhecido’ mas o que é inconsciente é muito pouco conhecido [...]”. (p. 304). Buscando equilíbrio não devemos tomar a consciência racional com superioridade, tão pouco deixar as forças irracionais inconscientes tomarem o lugar da consciência. "Se tivéssemos uma consciência inferior seriamos todos loucos. O eu e a consciência do eu são de máxima importância”. (JUNG, 2012, p. 305)

Quando as forças irracionais tomam conta da consciência é como se estivéssemos diante de um cavalo selvagem e indomável "O cavalo representa a esfera do inconsciente instintivo. Ele é a massa de energia primitiva que exige uma direção consciente, simbolizada pelo cavaleiro ou cacheiro, para se tornar produtivo ao sentido 
Seria supérfluo enfatizar a consciência sem observar sua relação, com conteúdos inconscientes. Por isso a ênfase principal está na consciência, como apercepção dos conteúdos inconscientes. “Apercepção. É um processo psíquico pelo qual se articula um novo conteúdo com conteúdos semelhantes e já existentes de modo que se o considere entendido, apreendido ou claro”. (JUNG, 2012, p. 430)

No filme o pai de Grace diz: "Eu fiquei olhando aquele cavalo e percebi que o mesmo se passa comigo. E tenho duas escolhas. Eu posso lutar contra as coisas ou aceitá-las”.

Agora ele percebe o que antes não percebia, pois através do inconsciente se produz a consciência. Nas palavras de Jung (2012) “A parte inconsciente é uma espécie de segunda intenção que no decorrer do tempo poderia tornar-se consciente com a ajuda da intuição e através de uma reflexão mais profunda [...]”. (p. 203)

Tendo a oportunidade de, a partir, do seu relacionamento com Pilgrim se voltar à para si mesma, se perceber e refletir, Grace juntamente com seu cavalo, conseguem superar seus medos, e o que jamais puderam imaginar aconteceu: Grace monta em Pilgrim novamente, agora seu medo, não aceitação, dor e rejeição estão sob seu comando. Grace toma as redes de sua vida em suas mãos, e descobre o quanto ainda é capaz - Ela volta a sorrir.

\section{Considerações finais}

Não vivemos mais em busca da sobrevivência, o sentido de nossas vidas não é mais lutar para que possamos satisfazer nossas necessidades primárias. Com o desenvolvimento da tecnologia, o homem contemporâneo se encontra em uma estável sustentabilidade de suas necessidades de sobrevivência. O homem está cada vez mais perdido, debate-se e tateia a procura de uma base sólida, de algo firme, para em cima disso, construir o edifício de sua existência. É frequente e visível, o grande número de pessoas depressivas, estressadas, que não encontram o sentido de viver, ou levam uma vida completamente alienada desprovida de significado e valor.

O verdadeiro sentido da vida está escondido no interior de cada ser, daí nasce a necessidade de nos autoconhecermos.

O trabalho do psicólogo na prática da Equoterapia pode levar em conta a contribuição da psicologia profunda, de Carl Gustav Jung, promovendo uma interação analógica entre o relacionamento: praticante-cavalo, associado aos processos interiores do praticante. Atrás da interação com o cavalo como um símbolo, é possível estabelecer uma conexão entre conteúdos inconsciente e a situação emocional que está sendo vivida pelo praticante, pois, o símbolo revela aspectos inconscientes que precisam ser integrados a consciência. Sendo assim a medida que o praticante se relaciona com seus conteúdos psíquicos instintivos, 
através de sua interação com o cavalo, conteúdos inconscientes e reprimidos, podem ser alcançados, interpretações e compreensões acerca da relação cavalopraticante podem ser realizadas a fim de que possam ser integradas a consciência.

A prática da Equoterapia, até então, opera visando o desenvolvimento biopsicossocial de seus praticantes, essa visão se estende a partir da contribuição da psicologia Analítica Junguiana, junto a proposta do desenvolvimento do autoconhecimento através da prática da Equoterapia, para uma perspectiva de um desenvolvimento não só biopsicossocial, mas também espiritual, pois, como afirma Ronecker (1997) cada animal, enquanto representação simbólica, é uma referência de nosso labirinto interior, referindo se ao caminho iniciático de nosso desabrochar enquanto indivíduos e nossa da evolução espiritual. Nesta proposta, a Equoterapia opera abarcando não somente o desenvolvimento de pessoas com deficiência e/ou com necessidades especiais, mas, todo e qualquer indivíduo que anseie pela busca do conhecimento de si mesmo e o significado de sua vida.

\section{Referências}

ADÁRIO, Y,S. Equoterapia: Um Metodo Terapeutico. (2005) Psicopio: Revista Virtual de Psicologia Hospitalar e da Saúde. Belo Horizonte. Disponível em:

<http://susanaalamy.sites.uol.com.br/psicopio_n2_48.pdf>. Acesso em o1 JUN. 2012.

Chevalier, J \& Gheerbrant, A, 2005. Dicionário de Símbolos. Ed. José Olympio, Rio de Janeiro, 1982.

EDINGER, E. F. Ego e arquétipo: uma síntese fascinante dos conceitos psicológicos fundamentais de Jung. São Paulo: Cultrix, 1972.

FERRARI, J, P. A Prática do Psicólogo na Equoterapia. (2003) (Monografia) Trabalho de Graduação Interdisciplinar- Faculdade de Psicologia, Faculdade Presbiteriana Machenzie, São Paulo. Disponível em: <http://www.equoterapia.com.br/artigos/artigo-14.php.> Acesso em o1 JUN. 2012.

MACHADO,J,A,C; ROCHA,J,R; SANTOS, L, M; PICCININ. A. (2008) Terapia Assistida por Animais. Revista Científica Eletrônica de Medicina Veterinária. São Paulo. Disponível em: $<$ http://www.revista.inf.br/veterinaria1o/revisao/edic-vi-n1o-RL86.pdf>. Acesso em o1 JUN, 2012.

Mindell, A. O corpo onírico: o papel do corpo no revelar do si-mesmo. São Paulo: Summus editora, 1989.

Mindell, A. Trabalhando com o corpo onírico. São Paulo: Summus editora, 1990.

HARK, Helmut. Léxico dos conceitos junguianos fundamentais. São Paulo: Loyola, 1988.

HOPCKE, Robert. Guia para a Obra Completa de C. G. Jung. Petrópolis: Vozes, 2012.

Jung CG. O Homem e seus Símbolos. Rio de Janeiro: Nova Fronteira, 2008.

. Ab-reação, análise dos sonhos e Transferência. Petrópolis: Vozes. (Obras completas de C. G. Jung v. XVI/2), 2012.

. Estudos experimentais. Petrópolis: Vozes (Obras completas de C. G. Jung v. VI), 2012.

. O eu e o inconsciente. Petrópolis: Vozes. (Obras completas de C. G. Jung v. VII/2), 
ROSSATO, L.

2012.

. Presente e Futuro. (2012). Petrópolis: Vozes (Obras completas de C. G. Jung v. X/1), 2012.

. Tipos psicológicos. Petrópolis: Vozes (Obras completas de C. G. Jung v.VI), 2012.

. Vida simbólica I. Petrópolis: Vozes (Obras completas de C. G. Jung v. XVIII/1), 2012.

. Vida simbólica II. Petrópolis: Vozes (Obras completas de C. G. Jung v. XVIII/2), 2012.

RAMOS, D. A psique do corpo. São Paulo: Summus Editorial, 2006.

RAMOS, D. G., Biase, M. C., Baltazar, M. H. M., Rodrigues, M. L. P., Sauaia, N. M. L.,Sayegh, R.R., Malta, S. M. C. Os animais e a Psique. São Paulo: Summus Editorial, 1999.

ROBERT, J, A. "Innerwork - A chave do reino interior". São Paulo: Mercuryo, 1986.

RONECKER, J. P. O simbolismo animal: mitos, crenças, lendas, arquétipos, folclore, imaginário. São Paulo: Paulus, 1997.

REDFORD, R. Título: The Horse Whisperer [Filme]. Produção de Patrick Markey, direção de Robert Redford. United States. 170min, 1998.

WOODMAN, M. A coruja era filha do padeiro. São Paulo: Editora Cultrix, 1980.

Submissão: 10.10.2018 / Aceite: 20.12.2019 